\title{
From the Editor-in-Chief's Desk: Continuing the Crucial Focus on the Employer-Employee Relationship
}

\author{
Melissa A. Parris
}

Published online: 19 April 2011

(C) Springer Science+Business Media, LLC 2011

As the incoming Editor-in-Chief for Employee Responsibilities and Rights Journal, I am both honored and humbled to be able to serve in this new capacity for a journal that provides a unique contribution to the academic field of employee relations. The journal's focus on examining various aspects of the employment relationship from the perspective of both employers and employees is one I strongly identify with, and I am excited to be continuing the aim of ensuring both a critical focus and academic rigor are applied to a consideration of the interpersonal, organizational, and societal outcomes both locally and globally.

In taking on this role, I owe a large debt of gratitude to the outgoing Editor-in-Chief, Margaret Vickers, for the strong foundation she leaves for the current editorial team. I want to take this opportunity to thank her for the clear leadership and direction she has provided for the journal over many years, which has resulted in strong growth in both the quality and reach of our publications. I am very pleased that Margaret has agreed to continue to serve the journal as an Editorial Board member, and we are truly fortunate to maintain her expertise and guidance for authors within this role.

My intention is to build on the existing strengths of Employee Responsibilities and Rights Journal, in providing an international and interdisciplinary forum for research and commentary on the employment relationship that recognizes emerging issues and ideas. In pursuing this aim, I am delighted to continue working with the existing editorial team. Patricia Simpson remains in her role as Associate Editor, and we will continue to work closely in managing the review and revision process. Victor Devinatz, as Perspectives Editor, provides an invaluable contribution to the journal, one that continues in this issue with an insightful article by Wray and Allsop bringing both an insider and critical perspective to an historical union event in the United Kingdom. I am greatly appreciative of the talent and energy Victor and Pat bring to the journal.

We are also fortunate to have a dedicated and experienced Editorial Board, and I want to thank them for their ongoing support of the journal and our authors. My gratitude also goes to our many ad-hoc reviewers who provide their expertise.

M. A. Parris $(\bowtie)$

Deakin University, Melbourne, Australia

e-mail: melissa.parris@deakin.edu.au 
The articles in this issue reflect our aim to examine issues that both cross national borders and have global implications with respect to employee relations. These articles cover a diverse range of topics including employee accountability, the facilitation of gender transition in the workplace, issues in the disclosure of union interest, and growth in the use of corporate social networking sites. I trust you'll find these interesting and a prompt for reflection in your own research and practice.

As we move forward, I welcome any suggestions, feedback, and/or contributions to the journal you may have. In particular, we intend to publish special issues at various times on areas of particular interest to our readers. If you would be interested in being the guest editor of a special issue, I would be pleased to speak with you about your ideas. I look forward to working with our current and future community of scholars and practitioners in the ongoing advancement of debate, analysis, and practical outcomes for employees and employers through Employee Responsibilities and Rights Journal. 